\title{
Movimientos sociales y protestas en los mundos rurales latinoamericanos: nuevos escenarios y nuevos enfoques
}

NORMA GIARRACCA*

\section{Introducción}

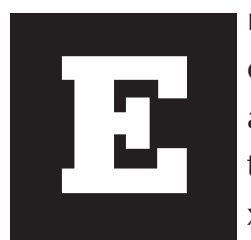

n la última década del siglo $\mathrm{XX}$, los problemas de los campesinos y de los indígenas de América Latina vuelven a ocupar un espacio importante en la agenda política internacional. La rebelión de los indígenas en Chiapas, México, en el primer día de 1994; las acciones cada vez más coordinadas, complejas y públicas del Movimiento de los Sin Tierra en Brasil, los levantamientos de los campesinos ecuatorianos y bolivianos, nos enfrentan a la magnitud y relevancia de este fenómeno.

Desde fines de los años de 1970, las acciones de los pobladores rurales - campesinos, farmers, obreros rurales - habían entrado en una etapa de latencia o de casi invisibilidad y las pocas protestas que los involucraban no lograron atravesar los límites locales o, excepcionalmente, nacionales. El efecto de las reformas agrarias en el marco de regímenes de acumulación internamente orientados, así como de la expansión agroindustrial con integración de la agricultura familiar, configuraron escenarios donde los

*Socióloga, Profesora-investigadora del Instituto Gino Germani. Universidad de Buenos Aires. Coordinadora del Grupo de Estudios Rurales de la UBA. E-mail: giarracc@mail.retina.ar 
campesinos y sus familiares se articulaban a los mercados (de productos, de tierra, de crédito y también de trabajo) y se percibía la fuerte esperanza de lograr una mayor integración económica para los mundos subalternos agrarios a partir de esta conexión, aunque tales relaciones comportaran fuertes asimetrías sociales.

Simultáneamente, el debate académico se centraba en los mecanismos de subordinación de estos sectores y en los márgenes de negociación frente a las empresas procesadoras o de fabricantes de insumos. Si bien, por un lado, se contaban por millones los campesinos que aún quedaban fuera del mercado y de la expansión agroindustrial ${ }^{1}$ y, por otro lado, los datos acerca de la población rural registraban una marcada disminución, la posibilidad de integrar los campesinos a una "vía agroindustrial de modernización" se sostuvo desde las políticas públicas y se celebró desde los "estudios campesinos".

Los estados nacionales fueron un soporte fundamental para esta relación agroindustrial; en muchos casos se caracterizaban como programas de desarrollo "tripartitos" (campesinos, empresas agroindustriales y Estados). El conflicto social, mientras tanto, se centraba en el contrato agroindustrial; en el logro de un acceso más justo a los créditos o en la relación con el Estado para mejorar su intervención. Asimismo, como muchos trabajadores rurales trabajaban para grandes empresas agroindustriales (en sus tierras o en sus empresas procesadoras), éstas se convirtieron en los centros de reclamos de campesinos y de trabajadores rurales y agroindustriales. Recordemos, como ejemplo, los conflictos con las empresas paraestatales en México (Tabamex, Inmecafé, etc.), durante los años de 1970.

Esta situación se fue modificando a medida que los gobiernos de la región, acompañados por los organismos internacionales, comenzaron a

1 De Janvry et al. (1989) estimaba alrededor de 7 millones de explotaciones de tipo "subfamiliar" y sostenía que eran las que más habían crecido en los últimos treinta años. 
generar políticas tendientes a la liberalización de las economías nacionales orientadas a crear una economía abierta y globalizada. Así, los nuevos créditos provenientes de los organismos internacionales comenzaban a otorgarse condicionados a severas políticas de ajuste. En el nuevo marco de políticas macroestructurales, el Estado retiraba paulatinamente los apoyos imprescindibles para mantener la "integración" de las agriculturas campesinas a la expansión agroindustrial. Las medidas generales impulsadas por el nuevo modelo se orientaron a liberalizar el comercio exterior, a una apertura general al mercado mundial y a la formación de mercados regionales como la North American Free Trade Association (NAFTA) y el Mercado Común del Cono Sur (Mercosur).

Las consecuencias del nuevo modelo económico neoliberal son bien conocidas en lo que se refiere a los procesos de concentración de la riqueza, acentuación de las desigualdades sociales, aumento de la pobreza y de la desocupación. En el nivel de las agriculturas, la apertura exterior requirió de nuevas reglamentaciones para desarmar aquellas redes institucionales desde las reformas agrarias hasta las instituciones de fijación de precios mínimos - que habían sostenido a la pequeña explotación familiar durante décadas. La modificación del artículo 27 de la Constitución de 1917 en México, y el decreto de Desregulación Económica de Argentina, en 1991, fueron, tal vez, los ejemplos más elocuentes en esta dirección.

El escenario conformado por unas nuevas reglas económicas tendientes a crear economías de escala en la agricultura, con fuertes inversiones de capital, con tecnologías acordes a tales condiciones y altas productividades, arrinconó a gran parte de los sectores de la pequeña explotación. Además, seguían pendientes problemas de tierra (por reparto o titularizaciones), así como otras reparaciones históricas de las poblaciones indígenas o soluciones para la pobreza extrema de los trabajadores sin tierra, etc. A este mapa social de "derechos pendientes" se sumaban pérdidas de derechos adquiridos. Tales situaciones implican, casi siempre, condiciones de posibilidad positivas para la expansión de la conflictualidad social. Es más fácil, dicen 
Laclau y Mouffe (1985), que se generen conflictos en una situación de pérdidas de derechos adquiridos que en aquella otra donde esos derechos nunca echaron raíces.

Pero como toda situación social, la generada en las últimas décadas es compleja e implica racionalidades múltiples (y no una sola como desean creer los economistas neoliberales). Con el discurso económico neoliberal que redujo derechos sociales adquiridos, comenzó a circular, con más fuerza que nunca en nuestros territorios, un discurso liberal con alto contenido democratizador. En efecto, la puesta en marcha de unas reglas económicas que resultaban excluyentes de importantes sectores poblacionales, era acompañada con discursos de recuperación de formas democráticas de gobierno, de mayor respeto por las minorías, por las diferencias étnicas, por género, por respeto al medio ambiente, etc. Tales discursos circularon en el nivel de la globalización acompañando a los capitales y, a mi juicio, produjeron importantes impactos en los niveles locales además de los nacionales. Las Organizaciones No Gubernamentales cumplieron un relevante papel en la expansión de tales discursos. Por último, los avances de las tecnologías de comunicación, sobre todo Internet, coadyuvaron a romper con aislamientos y favorecer la circulación de tales discursos hasta en las regiones más aisladas geográficamente.

En síntesis, se presentó esta conjunción de condiciones que, por un lado, arrinconan y excluyen a los campesinos y a los trabajadores, pero que, por el otro, habilitan nuevas "oportunidades políticas" (Tarrow, 1997). Los gobiernos democráticos - aun los débiles - reconocen a los ciudadanos como portadores de derechos y admiten la posibilidad de demandar otros nuevos; este escenario y los discursos democratizadores (en varios sentidos), representan, junto con las condiciones económicas que los arrinconan, el marco en el que se generan y desarrollan los conflictos y acciones de la población rural de América Latina de la última década del siglo XX.

Pensar y reflexionar en el nivel de América Latina como una unidad, y sobre todo en relación con sus mundos rurales, puede conducirnos a 
generalizaciones estériles. La región tiene aspectos similares en relación con las políticas públicas que fueron impulsadas por los agentes de la globalización (Fondo Monetario Internacional, Banco Mundial, etc.). Además, no le costó mucho participar de una mayor integración internacional y de una mayor interacción cultural facilitada por las nuevas tecnologías de comunicación. Sin embargo, cada región, cada país, se constituyó en un escenario particular cuyos actores desplegaron procesos singulares e irrepetibles.

En este trabajo me ocuparé de las particularidades del Sur de América Latina, de los dos países con menor cantidad de poblaciones campesinas e indígenas: Uruguay y Argentina. Los conflictos agrarios que se desplegaron durante toda la década pasada en la Argentina y en los últimos años en Uruguay, tienen sus particularidades: la presencia de la explotación familiar capitalizada coexistiendo con grandes productores (Piñeiro, 1999).

En relación con los países del Cono Sur planteo una cuestión teórica: cómo conceptualizar las acciones que expresan diversos conflictos, diversos actores, diversos niveles de organización. ¿Podemos sostener que son "movimientos sociales" con todas las cargas de sentidos que tal concepto acarrea? Soy cautelosa y prefiero mantener el análisis en los niveles conceptuales de "acciones de protesta" y delimito aquellas acciones que incorporan, en efecto, el sentido de una "protesta" (más adelante definiré el concepto) de aquellas otras que comportan presiones al poder político tendientes a defender intereses sectoriales. A este último tipo de acciones las conceptualizo como "corporativas".

No obstante utilizar tales conceptos, parto del análisis más general de los "movimientos sociales" que permite sostener una mirada distinta (a la de décadas atrás) sobre estos procesos sociales. De allí que dedicaré un apartado a reflexionar acerca de las viejas y nuevas teorizaciones sobre los movimientos sociales campesinos de América Latina. Por último, me ocuparé de caracterizar las acciones de protesta del Cono Sur y me centraré en los conflictos agrarios de Argentina en los últimos años, basándome en información generada por nuestras propias investigaciones². 


\section{Los enfoques teóricos-metodológicos}

Durante la década de los años 1960, Erich Wolf, estudiaba los movimientos campesinos como formas de "luchas", en referencia a los grandes cambios.

...las rebeliones campesinas del siglo xx ya no son sólo simples respuestas a problemas locales, si es que alguna vez lo fueron. Son reacciones locales ante disturbios sociales de gran importancia que han sido causados por importantes cambios de la sociedad....De este modo, cuando los protagonistas campesinos levantan la antorcha de la rebelión, el edificio de la sociedad ya está en condiciones que los exponen a ese fuego. Cuando la batalla haya terminado la estructura no será la misma (Wolf, 1973, p. 401).

La discusión giraba alrededor del problemas del nivel de "clasicidad" de las poblaciones campesinas, en comparación con el de la clase obrera, que estaba destinada a tener el rol protagónico en los grandes cambios revolucionarios.

¿En qué medida se puede hablar del campesino como clase? se preguntaba Eric Hobsbawm (1976). El problema residía en establecer su conciencia de clase y, en tal sentido, la mayoría de los estudiosos de la época coincidieron con Shanin (1966) en considerarlo un sector de baja "clasicidad". La personalización de las relaciones sociales, a través del clientelismo, el parentesco artificial como el compadrazgo, así como la expansión de la política de tipo faccional (Alavi, 1976), impedían la existencia de una conciencia de clase permanente.

Los campesinos tendían a relacionarse con sectores urbanos (clase obrera, intelectuales, etc.) para superar esta limitación tan esencial. Y allí

2 Grupo de Estudios Rurales - UBA. 
residía la segunda clave de los estudios de los movimientos campesinos de unas décadas atrás: la importancia de poder contar con intelectuales simpatizantes. La tercera clave, en aquellos sugerentes estudios, residía en centrarse en el papel del campesinado medio.

En efecto, no eran los más pobres los llamados a levantarse, porque, como sostenía Hobsbawm "Por muy militantes que sean los campesinos, el ciclo de sus faenas los ata a su destino" (p. 124). La militancia y la participación en las organizaciones recaían en los campesinos medios, con mayores dotaciones de recursos - materiales y simbólicos - para la acción política.

La acción campesina se comparaba con las acciones políticas de la clase obrera, que tenía mayor nivel de conciencia de clase, mayor homogeneidad en tanto no poseedora de medios de producción y que establecía un vínculo con las vanguardias revolucionarias (partidos, intelectuales) de distinta naturaleza. En América Latina, como en el resto del mundo subdesarrollado, los trabajadores rurales estuvieron demasiado entreverados con las comunidades campesinas como para considerarlos sujetos políticos comparables a los obreros industriales.

Los campesinados protagonizaron grandes movimientos políticos durante las seis primeras décadas del siglo XX, pero las corrientes más ortodoxas del marxismo los colocaron siempre "bajo sospecha". La condición de poseer o controlar tierra y sus apegos a tradiciones culturales que no contaban con las simpatías de los intelectuales "modernizadores" (por ej. la comunidad) contribuyeron a esta situación. El actor del cambio político se construía en referencia al capitalismo y a sus reglas de funcionamiento, donde las relaciones de propiedad eran fundamentales.

A partir de las grandes transformaciones que comenzaron a manifestarse en la década de 1980 y continuaron con más fuerza en la última década del siglo XX, la situación de los campesinos, sus movimientos y luchas así como los paradigmas de las ciencias sociales para comprenderlos, 
también cambiaron. Por un lado, obtuvieron reconocimiento como actor social capaz de protestar, reclamar, generar acciones colectivas. El hecho de que otros sujetos de cualquier origen social fueran aceptados como centro de los "nuevos movimientos sociales ${ }^{3}$ condujo a una revisión, dentro de las ciencias sociales, de aquellas teorizaciones que estrechaban las oportunidades de acción política de cualquier actor social. Se comenzó a pensar la política como un modo de presentación de lo social, sin sujetos privilegiados "a priori".

Por otro lado, los movimientos agrarios de la actualidad no manifiestan las pretensiones revolucionarias de otros tiempos (tomar el poder); sus demandas son variadas: persistencia en la producción, autonomía, participación, democratización (intensificación de procesos de ciudadanización). Tal vez el caso más paradigmático sea el movimiento indígena de la Selva Lacandona de Chiapas. La gran variedad de "formas de acción" que han desplegado -desde el levantamiento armado de comienzos de 1994, hasta "la poética" que apela a sentimientos profundos y simpatías de los sectores medios pasando por una marcha por México en estos primeros meses del 2001 - no tiene como finalidad "tomar el poder" (a la vieja usanza revolucionaria) ni crear un partido político progresista (al nuevo estilo latinoamericano).

Los zapatistas, los movimientos indígenas de Ecuador, de Chile, así como el Movimiento de los Sin Tierra en Brasil, la aparición de Vía Campesina en el nivel internacional (véase Giarracca, Teubal y Domínguez, 2001) son fenómenos sociales originales que se resisten a ser comprendidos con los viejos paradigmas de las ciencias sociales.

Para sumar complejidad, recordemos que estos nuevos movimientos campesinos e indígenas no tienen, necesariamente, correlatos en la conducta electoral de los pobladores rurales. Como sostiene Fox (1996), para medi-

3 Jóvenes de clase media sin acceso a créditos que "tomaban" casas desocupadas en Europa o rechazaban el mandato de servir militarmente a sus naciones - objetores de conciencia -, madres de todas las condiciones sociales que reclamaban por sus hijos desaparecidos, etcétera. 
ados de los noventa y en términos generales creemos que la situación no varió mucho: las regiones rurales de América Latina apoyan electoralmente a los partidos conservadores debido a las redes clientelísticas muy consolidadas en las regiones donde predominan las antiguas organizaciones gremiales.

Estas situaciones de los mundos rurales no son ajenas a muchos otros cambios acaecidos en escenarios políticos, económicos, tecnológicos, sociales y culturales globales. Y el pensamiento social no fue ajeno a estos procesos; las ciencias sociales sufrieron sus propios virajes y las nuevas interpretaciones pos-estructuralistas encararon las novedades desde otros horizontes. La reproducción y la transformación social se encaró desde la reflexión acerca de las condiciones que habiliten la formación de "actores" capaces de "intervenir en un estado de las cosas", capaces de producir nuevos sentidos. Se resignificó el concepto "estructura", se mostró que, como todo sistema de significantes, los mundos sociales son susceptibles de "comprensiones" y no de "explicaciones y predicciones". En tales virajes las disciplinas sociales perdieron pretensiones de cientificidad y recuperaron su pasado junto a las humanidades.

Alain Touraine, en su intento de reemplazar una representación de la vida social basada en nociones de sociedad, evolución y rol por otra, basada en nociones como historicidad, movimiento social y sujeto, fue uno de los pioneros en esta tarea. Los "movimientos sociales" (MS) aparecían en las nuevas teorizaciones como claves para comprender los nuevos tiempos. Touraine (1988) presentaba ciertos principios capaces de conceptualizar una relación como movimiento social y diferenciarlo de otros tipos de conductas colectivas y luchas. Definía al movimiento social como una acción conflictiva que cambiaba tanto las orientaciones culturales, como el campo de historicidad en forma de organización social, definidos a la vez por normas culturales generales y por relaciones de dominación social. Establecía tres principios: orientación cultural; control de la historicidad; lucha contra la dominación social. 
En la misma línea, Alberto Melucci ubicaba el concepto MS en el centro de una teoría procesual que recuperaba el conflicto para dar cuenta de sus dinámicas. Para que podamos adentrarnos en los análisis de los movimientos sociales - sostenía Melucci - es necesario que haya acciones colectivas y que éstas provoquen una ruptura en los límites de compatibilidad del sistema en el cual se sitúan, sea a nivel del mercado o del Estado. Una acción colectiva, nos decía este autor, implica la existencia de una lucha entre dos actores por la apropiación y orientación de los valores sociales y de los recursos. Pero la acción colectiva incluye también - agrega - un segundo aspecto: conductas que transgreden las normas que han sido institucionalizadas en roles sociales. Es decir acciones que tienden a una ruptura de los límites de compatibilidad del sistema dentro del que se encuentran situados. Los Movimientos Sociales están constituidos por acciones colectivas que cumplen con la primera y la segunda condición. De este modo, nos advertía, los MS no son objetos empíricos sino construcciones analíticas.

Esta analítica nos conduce a la búsqueda de significados de las acciones, al sujeto que las genera y a situarlas en el sistema de relaciones sociales. Nos permite ubicar el conflicto como límite de toda positividad y, por lo tanto, a limitar las pretensiones positivistas de viejo cuño de tomar lo social, como dado, naturalizado. Se comenzaban a reivindicar los mundos sociales y culturales, la vida cotidiana, las grandes pero también las pequeñas acciones de los actores, los grandes movimientos sociales pero también las pequeñas protestas.

Los autores europeos, entusiasmados además por los acontecimientos que ocurrían es sus países durante los años de 1980, buscaban las novedades de los movimientos sociales, a los que adjetivaron como "nuevos" y desde sus análisis proponían una mirada descentralizadora de las ubicaciones estructurales de los sujetos (la clase). Los Nuevos Movimientos Sociales no respondían a demandas de clases ni buscaban posicionarse frente o dentro del "poder" entendido como estructura. 
Estas teorizaciones comenzaron a circular por América Latina. A mediado de la década de 1980 apareció uno de los primeros textos dedicados a la problemática: Los movimientos sociales ante la crisis. En este esfuerzo colectivo estimulado por CLACSO, producto de un seminario regional, el compilador del libro, Fernando Calderón, advertía la inmadurez teórica de la problemática si se consideraban las particularidades latinoamericanas. En la región, decía Calderón, los movimientos no aparecen claros ni definidos: la multidimensionalidad de las relaciones, los aspectos étnicos, locales, las historias políticas producen densos y complejos modos de aparición de conflictos y acciones.

Y efectivamente, el fluir de procesos diversos, con fuertes particularidades nacionales y regionales, que manifestaban las primeras respuestas a los "nuevos tiempos", sostenían el temprano resquemor de Calderón. Pero también, vale decirlo, se iban generando conflictos y acciones con características desconocidas hasta entonces y diversos estudios empíricos que los registraban desde abordajes no tradicionales. Podríamos mencionar, a modo de ejemplo, el impresionante movimiento por los derechos humanos que se generó desde el Sur del continente o los insistentes intentos campesinos para lograr autonomía en México a través de las grandes marchas de la Coordinadora Plan de Ayala a la ciudad de México o las primeras acciones del Movimiento Sin Tierra en Brasil.

Como sostiene Fox (1996) a fines de 1980, el MST pasó a asumir un papel dominante en las acciones más radicales y directas a favor a la implantación de una Reforma Agraria en Brasil, en tanto en México, la formación de "redes", "coordinadoras" buscaban estructuras organizativas de tipo horizontal entre los campesinos. En casi todos los casos aparecían otros actores: la Iglesia Católica, las ONG's, etcétera. La pregunta que rondaba entre los estudiosos era que "novedades" de estas acciones campesinas habilitaban a tratarlas como "nuevos movimientos sociales".

Una pionera respuesta a tales interrogantes fue la de David Slater, quien en su temprano trabajo acerca de los NMS y el Estado en América 
Latina (1985), resaltaba la mercantilización, masificación y burocratización como rasgos acompañantes de la globalización económica. Se colonizaban todos los espacios de la vida, se mercantilizaban hasta los bienes simbólicos y los rituales sagrados, aumentaba la burocratización sumando a las estructuras nacionales las internacionales, etcétera.

De este modo, sostenía Slater, aparecían nuevas formas de subordinación y opresión y, simultáneamente, se ponía de manifiesto una ruptura con la idea de la constitución de una identidad social plena (la clase) que daba lugar a la representación política. Valiéndose de la conceptualización de Ernesto Laclau, el autor agregaba que las nuevas luchas habían provocado una crisis en tradicionales paradigmas de las Ciencias Sociales, en referencia a la caracterización de los agentes sociales y sus conflictos. El conflicto social, en su antigua versión, se caracterizó por tres rasgos:

1) las identidades estaban dadas por la posición en la estructura social;

2) el tipo de conflicto estaba determinado por el paradigma evolucionista (feudalismo-capitalismo; capitalismo-socialismo, etc.);

3) el espacio del conflicto era la política donde se representaban los intereses dados por la ubicación económica de los agentes.

Con la aparición de los NMS, la unidad de estos tres aspectos del paradigma se rompería: los actores ya no podían ser caracterizados por su ubicación en la estructura de la producción sino que resultaban de varias posiciones, de varias ubicaciones (posiciones de sujeto en la conceptualización de Laclau y Mouffe, 1985).

Las reacciones contra esta analítica dentro de los estudios campesinos provenían del lado del marxismo más ortodoxo y no se hicieron esperar. En efecto, Tom Brass, uno de los editores de Journal of Peasant Studies, criticó esta posición y la consideró inaceptable para los estudios de América Latina. La crítica recaía, por supuesto, en la desvalorización de la analítica centrada en las "clases sociales" para caer nuevamente - según Brass en posiciones neopopulistas en las que se perderían las dimensiones polí- 
tico-ideológicas (Brass, 1991).

A mi entender, Brass no puede comprender (o aceptar) los nuevos modos de pensar los aspectos políticos e ideológicos en las acciones colectivas de los mundos rurales de América Latina. Éstos no se pierden sino que se los comprende de otro modo. Las nuevas teorizaciones toman los conflictos que hacen a las dimensiones económicas y por lo tanto, parten de una ubicación de los actores en la estructura agraria. Aunque haya dejado de utilizarse la clásica conceptualización marxista (que en los mundos agrarios trajo bastante malentendidos) se ubica, se posiciona socialmente a los sujetos. Pero a las demandas de tipo social, los nuevos enfoques suman otras: la búsqueda por los derechos de las minorías, las diferencias por género, por etnias; menor corrupción, mayor participación en planes de gobiernos, por ejemplo.

Además, los reclamos no provienen necesariamente de una supuesta "identidad de clase", sino que, por ejemplo, en los "Sin Tierra" participan pobladores rurales y desocupados urbanos, o bien en movimientos tales como El Barzón, en México, y las Mujeres Agropecuarias en Lucha, en Argentina, participan productores con cierto capital (las conceptualizaciones tradicionales no dudarían en ubicarlos como "pequeñas burguesías").

El debate entre marxistas ortodoxos y pos-estructuralistas pierde todo sentido intelectual frente al avance del denominado Movimiento Campesino (Vía Campesina entre otros), que en realidad incluye una serie de sectores y de demandas que van desde los productores familiares europeos a los "consumidores concientes" pasando por las demandas indígenas, las de los trabajadores sin tierra, etc. Aquella vieja discusión fue agotándose frente al protagonismo de las Ilamadas genéricamente "luchas campesinas" que en el nivel mundial impactan en este nuevo milenio de un modo realmente inesperado y sorprendente.

EL nuevo dispositivo conceptual permitió no sólo comprender los grandes movimientos que conmueven al mundo (como Chiapas o el MST) sino 
otras expresiones de conflictos, protestas, como también considerar las estrategias de los actores en los niveles productivos, en los mercados laborales o en el de la participación en las pequeñas organizaciones. Todo ello nos permite vislumbrar un mundo rural activo, adaptándose o resistiendo a las nuevas condiciones, produciendo rupturas o pequeñas reformas o, en última instancia, buscando estrategias urbanas o migratorias. Tales imágenes sustituyen esas otras donde una "globalización" o "un mercado" arrasan, inevitablemente, con las regiones "inviables" (como alguna vez las definió el Banco Mundial).

\section{La especificidad del Cono Sur żacciones colectivas o acciones corporativas?}

Argentina y Uruguay fueron países de América Latina donde coexistieron la estancia ganadera, de considerables extensiones, con explotaciones pequeñas y medianas de tipo familiar capitalizada, dedicadas a las agriculturas y agroindustrias (caña, yerba, arroz, etc.). Piñeiro suele caracterizar al Uruguay como un país "pastoril", con un estancamiento relativo de este sector ganadero a partir de la crisis del 1930 (Piñeiro, 1995; 1999). Otro tanto ocurrió en la misma época en la Argentina, aunque el sector terrateniente pampeano siguió manteniendo un poder político relativo por muchas décadas más.

En las estructuras agrarias de ambos países se destacan los estratos de productores medios y familiares y, si bien a lo largo del siglo el número de hectáreas promedios por explotaciones aumentó y el peso relativo de las explotaciones medias y familiares disminuyó, este tipo de productor - a través de sus entidades representativas la FAA y $\mathrm{CNFR}^{4}$ - son actores relevantes en los mundos sociales del agro de ambos países.

En un trabajo de la década de 1980, Diego Piñeiro (1985) intentó conceptualizar como "campesina" a la agricultura familiar de los estratos

4 FFA es la Federación Agraria Argentina y la CNFR es la Comisión Nacional de Fomento Rural de Uruguay, ambas creadas en la primera década del siglo xx (1912 y 1915 respectivamente). 
más bajos de superficie de la agricultura uruguaya y, muy influido por el trabajo de Scott (1976), se propuso registrar las acciones individuales de resistencia a la explotación capitalista.

En la medida en que su poder político no era efectivo - sostenía Piñeiro - y en la medida en que las organizaciones de productores tampoco podían ser efectivas debido al contexto político reinante en el país [se refiere a las dictaduras militares] las formas de resistencia al nivel de la unidad doméstica fueron las más relevantes (p. 164).

En Argentina, durante los años setenta, se había generado un movimiento de pequeños productores en el Norte del país: las "Ligas Agrarias". Ese movimiento tuvo demandas heterogéneas (tierra, precios, créditos, etc.) y formas de luchas novedosas dentro de la tradición agraria argentina. Abordado en los primeros momentos con analíticas tradicionales de las ciencias sociales, el movimiento fue objeto de muy diferentes interpretaciones. Hubo quienes lo consideraban parte de las luchas populares con alto contenido revolucionario (Ferrara; Francisco, 1973) o quienes calificaron esas luchas como movimientos de tipo populistas con reivindicaciones "pequeño burguesas" (Bartolomé; Leopoldo, 1978).

Pero en ninguno de estos dos países, los pequeños productores ni sus resistencias pueden atribuirse el peso nacional que lograron en países como México, Brasil, Bolivia. En primer lugar, por el papel marginal de estos sectores en la sociedad global de ambos países, dados sus altos niveles de urbanización; en segundo lugar, porque los asentamientos de los agricultores fueron el resultado de procesos de colonización (a veces conflictivos) y las "reformas agrarias" no constituyeron banderas políticas. Uruguay es un país de "propietarios" y tales derechos son sólo cuestionados por posiciones muy radicalizadas. En la Argentina los colonos accedieron a la tierra básicamente a partir de un acontecimiento que conmovió al próspero país 
del "centenario", en 1912: el Grito de Alcorta"5. Este temprano acceso a la tierra los convirtió en pequeños propietarios recelosos de consignas de los partidos de izquierda que eran los únicos que levantaban la necesidad de una reforma agraria, partiendo del supuesto (nunca comprobado) de que el gran terrateniente pampeano era "un latifundista" (véase al respecto Giarracca, 1999).

Las acciones de los campesinos "rioplatenses" no son fácilmente comparables a las de los campesinos de Brasil, Paraguay o México. Pero hay otro aspecto que tenemos que considerar: muchas de las protestas del agro de ambos países estuvieron, y aún hoy están, conducidas por los productores - agrarios y pecuarios - más grandes.

Es necesario, por lo tanto, diferenciar demandas y orientaciones dentro de los "bloques" que se presentan como la "protesta del campo" tanto en Uruguay como en Argentina. Como sostiene Piñeiro en relación con su país:

Por lo mismo que es esta la base social de la protesta, no hay reclamos de carácter estructural. No se habla de los procesos regresivos en la distribución de la tierra, de los procesos de concentración de los activos físicos, de políticas diferenciadas para los pequeños y medianos productores. No se habla de la creciente extranjerización de la tierra. Sólo se reclama por los precios de los productos, por las deudas y los impuestos que ahogan al campo. Uno de los lemas de este conflicto ha sido "rentabilidad o Muerte". Son reclamos de un empresariado que quiere que se le asegure rentabilidad en su explotación (1999, p. 25).

5 El “centenario" de la Revolución de Mayo de 1810, encontró al país en crecimiento y próspera inserción en el capitalismo internacional. En 1912, los arrendatarios, productores de cereales, de la provincia de Santa Fe iniciaron un movimiento tendiente a lograr una mejor posición en el reparto del excedente agrario. La propiedad de la tierra fue una de sus principales consignas. 
En efecto, si bien en Uruguay existen reclamos de sectores subalternos del agro - pequeños horticultores, sectores empobrecidos de la agricultura familiar, trabajadores rurales, etc. - no son ellos, como actores, quienes aparecieron en la protesta de 1999. Las demandas empresariales, de carácter corporativas, son las que se visualizan tanto en las formas de acción como en la simbología del episodio de aquel año.

Otro tanto ocurre en Argentina cuando se trata de conseguir financiaciones o cambiar los precios relativos sin tocar la convertibilidad como se ocupan de aclarar las entidades - en movilizaciones y paros destinados a conseguir mejores condiciones de negociación con los funcionarios que, por otra parte, siempre los reciben en sus despachos y escuchan atentamente los reclamos. Esas movilizaciones son convocadas por las cuatro entidades del agro, pero están hegemonizadas por la tradicional Sociedad Rural Argentina.

A mi entender, en tales situaciones estamos en presencia de acciones corporativas, llevadas a cabo por las entidades con la necesaria capacidad de lobby para mejorar posiciones relativas. Schmitter (1987) define a las acciones de tipo corporativo como un sistema de representación reconocido y autorizado por el Estado, que se les ha otorgado el monopolio deliberado de la representación, a cambio de observar ciertos controles en la selección de sus dirigentes y en la articulación de las demandas y apoyos (1987, p. 10). Otra lógica implícita en este tipo de representaciones es el de la homogeneidad en tanto se habla de "un campo", "los productores". De este modo, las diferencias y asimentrías internas que pujan por expresarse son tapadas en aras de la búsqueda de un solo actor, un solo campo.

La habilidad de los sectores de grandes propietarios, en Uruguay y Argentina, consiste en articular sus demandas con los sectores más golpeados por los ajustes presentando "un campo" en peligro, una unidad donde aparecen como "iguales" los pequeños productores empobrecidos, los trabajadores sin tierra y los propietarios de más de 1.000ha o de más de 5.000ha en ambos países, respectivamente. 


\section{La nueva protesta agraria en Argentina}

Defino "la nueva protesta agraria" en Argentina como el conjunto de acciones que comienzan a desplegarse e intensificarse a partir de los cambios institucionales que resultaron del decreto de desregulación económica generado por la presidencia de Carlos Menem, en 1991 y que duró 10 años.

La medida de política económica marcó un límite temporal importante debido al efecto producido en los procesos agrarios y los mundos rurales. Con esta medida, se disolvieron la mayor parte de las normas regulatorias, así como las instituciones que las llevaban a cabo y que habían permitido, a partir de las primeras décadas del siglo xx, la coexistencia de las pequeñas y medianas explotaciones agrarias con la gran explotación agraria ganadera o mixta.

El tipo de acción desarrollada por los distintos sujetos de los mundos rurales, tanto sean productores, trabajadores, como desocupados o comerciantes de pequeños poblados, la caracterizamos como "acciones de protesta", entendiéndolas como una subclase de las acciones colectivas que suponen intervenciones no convencionales en los espacios públicos para influir en quienes toman decisiones políticas. La protesta es un recurso político de quienes carecen de poder para hacer conocer sus demandas y se caracteriza por desarrollar formas de acción novedosas, no ortodoxas y con objetable legitimidad (Della Porta y Diani, 1999). La protesta social supone el fracaso de las instituciones en relación con sus capacidades para "oír, entender y resolver" los problemas de los ciudadanos. Las acciones de protesta, dice Grossi (1989), tienen como objetivo la transformación de los valores políticos dominantes y de las reglas del juego relativas al proceso de influencias sobre el poder (p. 41).

La nueva "protesta agraria", en Argentina, comenzó con grandes marchas de tipo corporativo de los gremios que representan a productores medios y pequeños. Pero, a diferencia de lo que ocurriera en décadas anteriores, estos primeros eventos estuvieron hegemonizados por las enti- 
dades que nuclean a los pequeños y medianos productores y no intervino la Sociedad Rural Argentina. Esta situación particular en el campo que dividía a las cuatro entidades corporativas, así como la falta de coherencia de los dirigentes de tales organizaciones en la demanda de políticas para el sector, presagiaban lo que ocurriría durante la década.

Desde fines de 1991 hasta julio de 1993, se habían registrado protestas locales como la de los fruticultores del Valle de Río Negro o la de los cañeros de Tucumán; pero la protesta se hace visible - pública y nacionalizada - a partir de la marcha agraria del 27 de julio de 1993. Ese día, los agricultores familiares de todo el país ganaron el espacio público de la Plaza de Mayo y demostraron su desacuerdo con las políticas económicas neoliberales (véase Giarracca y Teubal, 1993). Desfilaron con sus tractores los agricultores nucleados en la Federación Agraria Argentina (FAA) y en la CONINAGRO (la federación de tercer grado del movimiento cooperativo agrario). La voz cantante la llevó, sin dudas, la FAA bajo la presidencia de un viejo luchador y reconocido representante del sector de los chacareros ${ }^{6}$. Fue una marcha del campo de los agricultores y los representantes de las grandes empresas agrarias y agroindustriales nucleadas básicamente en la Sociedad Rural Argentina (SRA) estuvieron ausentes.

Esta organización de grandes terratenientes (SRA) había sido protagonista principal de los reclamos de la década de los años de 1980, bajo la presidencia de Raúl Alfonsín y había logrado articular a los pequeños y medianos productores a sus propios reclamos. Pero a partir del gobierno de Menem, ella se convertiría en un núcleo económico beneficiado por las nuevas medidas. A partir de 1989, las políticas públicas aparecían sesgadas a favor de grandes escalas de producción; la pequeña y mediana producción comenzaban a sentir el rigor de las políticas neoliberales pues las nuevas condiciones de funcionamiento les resultaban intolerables. De todos modos, en algunos pocos momentos de esta década, la Sociedad Rural Argen- 
tina llevó a cabo, con las tres organizaciones corporativas restantes, algunos paros agrarios debido a que evaluó que su propia rentabilidad agraria estaba en peligro. A partir de la devaluación y el reestablecimiento de los impuestos a las exportaciones - conocidos como "retenciones agripecuarias" - la vieja alianza corporativista se perfila nuevamente en este complicado 2002.

En 1994, los agricultores familiares volvieron a ganar la Plaza de Mayo, en esa oportunidad acompañando a todo el interior del país en lo que se conoció como la "Marcha Federal". Se perfilaba de este modo la separación de la Federación Agraria de la entidad de los grandes terratenientes y su alineación con la Confederación de Trabajadores Argentinos (CTA). Si bien el "modelo" en el nivel nacional aún mantenía cierto consenso, la ciudad capital - Buenos Aires - se conmocionaba con cada uno de estos encuentros.

Los elementos "novedosos" de las acciones de los actores del campo se manifestaron en plenitud a partir de entonces. Hizo su irrupción el "Movimiento de Mujeres Agropecuarias en Lucha", se consolidaba la corriente interna de FAA "Chacareros Federados", la organización "Movimiento Campesino de Santiago del Estero" (MOCASE) lograba una importante consolidación, comenzaban algunos cortes de ruta en varias provincias, volvieron a expresarse en huelgas de alcance provincial algunos trabajadores rurales y comenzaban a manifestarse los reclamos de los pueblos indios.

A nuestro entender, la "novedad" de la protesta reside, en primer lugar, en la aparición o el fortalecimiento de las organizaciones que nuclean a pequeños y medianos agricultores, campesinos, trabajadores rurales, pueblos indios. Es decir, se trata de sectores subalternos muy castigados por las políticas neoliberales. En segundo lugar aparece tal repertorio de acciones que permite reservar la "marcha"o "el paro agrario" para ocasiones excepcionales y ubicar en el espacio público acciones periódicas tales como "paros de remates de tierras endeudadas", "cortes de ruta", "toma de explotaciones", "toma de tierras", etcétera. 
La protesta social agraria en Argentina se intensificó dentro de la "protesta social nacional" que adquiría una magnitud inesperada, en los últimos años del gobierno del presidente Menem. En 1989, al comienzo de su gobierno, el número de "expresiones de conflictos" (medido por dos métodos diferentes) no sobrepasó los 200 por año pero, a partir de 1997, según las mismas fuentes, trepó a las casi 600 expresiones de conflictos por año. La intensidad y regularidad de los conflictos permiten caracterizarlos como "un ciclo de protesta", en el que, aún hoy, el país está inmerso. Durante este período aparecieron la "Carpa Blanca" de los docentes, los "escraches" a violadores de los derechos humanos, los cortes de las rutas estratégicas en el nivel de la comunicación nacional donde desocupados agrarios y pequeños poblados urbanos se convirtieron en "fogoneros y piqueteros" (véase Giarracca, N. y Gras, C. 2001), los "apagones" y muchas nuevas formas de acción.

En tal escenario de protesta, las acciones de los agricultores familiares, los conflictos de poblaciones indígenas para recuperar sus tierras, las nuevas articulaciones de los pobres del campo con los de los centros urbanos (en una marcha de 1998), las acciones de las "chacareras" endeudadas que decidieron no perder sus tierras, de los campesinos que resistían desalojos de viejos y nuevos terratenientes, las "caravanas" de los pueblos indios, cobraron un sentido que los diferenciaba claramente de las acciones corporativas que cada tanto, aún, llevan las cuatro entidades corporativas pivoteadas por la Sociedad Rural Argentina.

En 1998, durante una marcha a la Plaza de Mayo que se llevó a cabo unos pocos días después de inaugurarse la tradicional exposición de la Sociedad Rural Argentina en el centro de la ciudad, se acuñó la consigna "el otro campo". En su discurso inaugural el presidente de la SRA había sostenido "éste es el campo".

Los datos sobre protestas registrados durante los tres últimos años del siglo XX por una investigación que llevamos a cabo en la Universidad de Buenos Aires, dan cuenta de dos tipos de fenómenos: acciones de sujetos del sector agrario (productores, trabajadores, etc.) y, en segundo lugar, acciones en zonas de baja urbanización afectadas por las crisis del sector primario, llevadas a cabo por sujetos no necesariamente agrarios (desocupados de ingenios, docentes, etcétera). 
Cuadro 1. Tipos de sujetos participantes en la protesta agrorural 19971999. En porcentajes

\begin{tabular}{|c|c|c|c|c|}
\hline Sujetos sociales/año & $\mathbf{1 9 9 7}$ & $\mathbf{1 9 9 8}$ & $\mathbf{1 9 9 9}$ & Total \\
\hline Productores agrarios & 30.8 & 40.9 & 51.7 & 42.5 \\
\hline $\begin{array}{c}\text { Trabajadores } \\
\text { Rurales }\end{array}$ & 6.3 & 0.9 & 1.3 & 2.5 \\
\hline $\begin{array}{c}\text { Trabajadores } \\
\text { Agroindustriales }\end{array}$ & 11.9 & 6.5 & 10.6 & 9.5 \\
\hline Aborígenes & 8.0 & 8.8 & 7.6 & 7.4 \\
\hline Desocupados & 21.4 & 19.1 & 5.9 & 14.6 \\
\hline Otros & 21.6 & 23.8 & 22.1 & 24.5 \\
\hline Total & $\begin{array}{c}100.0 \\
(159)\end{array}$ & $\begin{array}{c}100.0 \\
(215)\end{array}$ & $\begin{array}{c}100.0 \\
(236)\end{array}$ & $\begin{array}{c}100.0 \\
(610)\end{array}$ \\
\hline
\end{tabular}

Fuente: Banco de datos del Grupo de Estudios Rurales - UBA.

Es interesante observar que el sujeto más importante de las protestas fueron los "productores agrarios", lo cual marca claramente la crisis sin solución institucional del sector. Luego tienen peso los "desocupados" y en tercer lugar aparecen los reclamos de los trabajadores (aunque sumáramos rurales y agroindustriales).

Cuadro 2. Formas de acción de las protestas agrorurales, 1997-1999. En porcentajes

\begin{tabular}{|c|c|c|c|c|}
\hline Formas de acción & $\mathbf{1 9 9 7}$ & $\mathbf{1 9 9 8}$ & $\mathbf{1 9 9 9}$ & Total \\
\hline Movilizaciones & 15.3 & 16.6 & 17.2 & 16.5 \\
\hline Cortes de ruta & 33.3 & 7.6 & 22.3 & 19.9 \\
\hline Ocupaciones & 3.3 & 9.0 & 10.3 & 8.1 \\
\hline $\begin{array}{c}\text { Asambleas, plenarios, reuniones } \\
\text { Abiertas }\end{array}$ & 19.3 & 35.5 & 12.2 & 23.1 \\
\hline $\begin{array}{c}\text { Otros (repudios, acciones judiciales, } \\
\text { desobediencia civil, etc.) }\end{array}$ & 10.8 & 16.1 & 19.7 & 21.2 \\
\hline Total & 100.0 & 100.0 & 16.3 & 11.2 \\
\hline & $(161)$ & $(215)$ & $(194)$ & $\begin{array}{c}100.0 \\
(569)\end{array}$ \\
\hline
\end{tabular}

Fuente: Banco de datos del Grupo de Estudios Rurales, UBA 
Como vemos en el cuadro 2, las "movilizaciones" y los "cortes de rutas" fueron las formas más frecuentes de protestar. En 1997 los cortes de ruta se impusieron como forma de acción, es el año de Cutral-Co y de la muerte de Teresa Rodríguez.

Sin duda, estamos frente a un nuevo tipo de protesta (en el escenario de la protesta social nacional) que incluye demandas sectoriales de campesinos, "chacareros", pueblos indios, trabajadores desocupados junto a otras dirigidas a obtener mayor autonomía, mayores inserciones como ciudadanos en la vida política y, la más importante, el derecho a la existencia como actores económicos y sociales diferentes a la supuesta "producción a gran escala" que repite el discurso oficial como "única salida". En todos ellos aparece un fuerte discurso acerca de una "identidad amenazada" que viene de orígenes étnicos (a veces en discusión, véase Domínguez, D. y Mariotti, D., 2000), del género - "las mujeres chacareras" -, o de ser parte de la descendencia de aquellos que poblaron unas tierras vacías en los comienzos del siglo XX y crearon pueblos y mundos sociales.

\section{Algunas reflexiones finales}

En este trabajo, me propuse reflexionar acerca de las acciones colectivas en los mundos agrarios y rurales de América Latina. Propuse pensar esta nueva etapa, difícil y compleja, para las poblaciones rurales desde las conceptualizaciones de una sociología de los movimientos sociales que recupere al sujeto su capacidad agencial, pero también que recupere al investigador como "intérprete" de significados y sentidos de los actores y sus producciones.

Para iluminar en términos comparativos la nueva propuesta teóricometodológica, dediqué algún espacio a recordar los paradigmas vigentes hasta fines de los setenta que abordaron los movimientos campesinos desde la centralidad del capitalismo y los modos para lograr transformaciones revolucionarias. El referente clásico fue "la clase obrera" y, a partir de allí, se trabajaba acerca de la baja "clasicidad" de los sectores campesinos. 
En las nuevas ontologías sociales postestructuralistas que reabrieron la discusión de "la acción social", los denominados estudios de Movimientos Sociales (MS) tuvo un papel central. La perspectiva de los MS permite considerar los procesos de institucionalización y de cambios de los órdenes sociales. Melluci sostiene que tanto las "acciones colectivas" como los "movimientos sociales" son niveles analíticos de la acción y no entidades empíricas (y esto es importante remarcarlo). Por su parte, Buechler y Kurt Cylke (1997) sostienen que muchas corrientes sociológicas están de acuerdo en que la sociedad es una creación social de la gente que luego, con frecuencia, olvida esta acción y "naturaliza" tales construcciones, las da por dadas. En el fondo de todo "orden social" hay un momento de ruptura, de des-orden producido por acciones disruptoras, que tradicionalmente se han conceptualizado como "movimientos sociales", "acciones colectivas", o en ocasiones como "revoluciones" y las "contrarrevoluciones" o "contrarreformas". Estamos en un nivel donde lo que está en juego es el sistema institucionalizado y las condiciones de posibilidad para modificarlo; la acción "en los límites de compatibilidad del sistema" como suele sostener Melucci.

Los movimientos sociales, sus actores, sus organizaciones son constructos sociales de difícil y compleja creación. El principal interrogante de las ciencias sociales en relación con ellos, gira acerca de las condiciones de posibilidad positiva para que tal cosa ocurra. No se trata de "conocer" a los "movimientos u organizaciones" (cómo si fuesen entidades empíricas), sino de analizar hasta qué punto ellos logran formarse como tales. Y en esta tarea es imprescindible orientarse a las dislocaciones de aquellas identidades sociales que aparecían como plenas, que no es otra cosa que el momento de expansión de la conflictualidad social. El momento en que las dislocaciones ponen en acto el carácter contingente de aquello que se nos presentaba como pleno, necesario y hasta cierto punto determinante. De allí además, la importancia que adquieren las nuevas acciones de protesta en escenarios políticos como el de Argentina. 
Las acciones colectivas o movimientos sociales pueden derivar en nuevas institucionalizaciones que contengan nuevos derechos, nuevos espacios democratizadores. No obstante los cambios institucionales también pueden provenir de los sectores más poderosos y orientarse a anular "derechos sociales" anteriormente conquistados como muy bien lo han demostrado varios gobiernos de corte "neoliberal" en los últimos años.

En estos escenarios de fuertes cambios institucionales que desatan conflictos entre los sectores económicos concentrados, es necesario diferenciar "acciones colectivas", con intenciones democratizadoras, de las "acciones corporativas", tendientes a defender privilegios e intereses económicos.

En el Sur de América Latina, sobre todo en la Argentina, después de un período en el cual el discurso de "la única salida" había logrado convertirse en hegemónico ("sentido común"), se abrió un período de grandes protestas y de nuevas e importantes acciones del movimiento social por los derechos humanos. En relación con la protesta nacional, los análisis dan cuenta de la diversidad de actores, de formas de acción, de demandas, de niveles de organización (Véase; Schuster, F. 1999; Scribano, A. 1999; Î́nigo Carreras, N., 1997).

En la protesta social agraria traté de diferenciar los eventos iniciados por las viejas alianzas, con demandas de tipo corporativas, de "la nueva protesta" (véase Alonso, J. et alii 1999; GER, 1999). Nuevos actores (mujeres en un mundo rural fuertemente patriarcal, "pueblos indios" en un país de fuerte ascendencia europea; por ej.); nuevos repertorios de acciones; nuevas demandas y los intentos de construcción de redes horizontales entre ellos y con los movimientos campesinos de América Latina, nos habilita a sostener que estamos en presencia de un nuevo tipo de protesta social.

Esta "novedad "del mundo social agrario argentino difiere de la situación uruguaya. Si bien allá los sectores subalternos están arrinconados por el discurso neoliberal y tienen problemas graves, la protesta de 1999 estuvo hegemonizada por los sectores más fuertes. Más que derechos reclaman 
privilegios, como ocurre también con la SRA en Argentina. En la protesta uruguaya se manifestó "un solo campo" y en Argentina se construyó un espacio de conflictos para "otro campo". Esa "otra situación" argentina es una condición de posibilidad positiva para la formación de un movimiento social. Y, por ahora, esta es una importante diferencia con Uruguay.

\section{Referencias}

ALAVI, Hamza. Las clases campesinas y las lealtades primordiales. México: Ed. Anagrama, 1976.

BRASS, Tom. Moral Economists, subalterns, new social movements, and the (re-) emergence of a (post-) modernised (middle) peasant. In: The Journal of peasant Studies, v. 18, n. 2, Gran Bretaña, 1991.

BUECHLER, S. y CYLKE Jr., F. Kurt. Social movements: perspectives and issues. EE.UU.: Mayfield Publishing Company, 1997.

CALDERÓN. Los movimientos sociales ante la crisis. México: UNU, 1986.

CARRERA, N. Iñigo y COTARELO, M.C. (s/f.) Relaciones de fuerzas en la Argentina actual. (De los 60 a los 90). Ponencia.

CARRERA, N. Iñigo y COTARELO, M.C. Las formas que toma la lucha social en la Argentina actual. En: Cuadernos del Sur, Buenos Aires, 1997.

DE JANVRY, A. et alii. Land and labour in Latin American Agriculture from 1950 to 1980. En: Journal of Peasant Studies, v.16, n. 3, 1989.

DOMÍNGUEZ, D. y MARIOTTI, D. Nuevas dinámicas de acción en el conflicto por la tierra. En: Revista de comunicación popular WAYRURO, internet, 2000.

FERRARA, Francisco. Qué son las ligas agrarias. Buenos Aires: Ed. Siglo XXI, 1973.

FOX, J. A política e as novas formas de organização camponesa na América Latina. En: NAVARRO, Z. (Coord.) Política, protesto e cidadania no campo. Porto Alegre: Editora da Universidade, UFRGS, 1996. 
Sociologias, Porto Alegre, ano 4, no 8, jul/dez 2002, p. 246-274

GIARRACCA, N.; TEUBAL, M. y DOMÍNGUEZ, D. El Foro Social Mundial: un paso más para "otro mundo posible". En: GIARRACCA, N. La protesta social en la Argentina: transformaciones económicas y crisis social en el interior del país. Buenos Aires: Alianza Editorial, 2001.

GIARRACCA, N y GRAS, C. Conflictos y protestas en Argentina de finales del siglo $X X$ con especial referencia a los escenarios regionales y rurales. En: GIARRACCA, N. La protesta social en la Argentina. Transformaciones económicas y crisis social en el interior del país. Buenos Aires: Alianza Editorial, 2001.

GIARRACCA, N. y TEUBAL, M. El movimiento de mujeres agropecuarias en lucha: las mujeres en la protesta rural en la Argentina. En: Realidad Económica, n. 15O, Buenos Aires, 1997.

GIDDENS, Anthony. La constitución de la sociedad. Buenos Aires: Amorrortu, 1995.

GOLSBERG, C. El movimiento agrario de misiones en un escenario en transformación. Tesis de Grado. Facultad de Agronomía, Universidad de Buenos Aires, 1999.

GROSSI, María. El cuestionamiento de la política partidaria: los movimientos de base en el Brasil. En: Critica \& Utopia, Revista Latinoamericana de Ciencias Sociales, Buenos Aires, 1989.

HOBSBAWM, Eric. Los campesinos y la política. México: Ed. Anagrama, 1976.

LACLAU, Ernesto. Nuevas reflexiones sobre la revolución de nuestro tiempo. Buenos Aires: Nueva Visión, 1993.

MELUCCI, Alberto. Sistema político, partidi e movimenti social. Milán: Feltrinelli, 1989.

MELUCCI, Alberto. The new social movements: a theoretical approach. En: Social Science Information, n. 192, EE.UU, 1980.

SLATER, David. Social Movements and a rescating of political. En: Slater (Ed.) New social movements and the state in Latin American. Amsterdam: Ed. CEDLA, 1985. 
SHANIN, T. Peasants and peasants societies. Londres: Penguin Books, 1966.

SCHUSTER, Federico. Protestas sociales en la Argentina: 1989-1996. En: Informe Anual sobre la situación de los Derechos Humanos en la Argentina, CELS, Buenos Aires, Argentina, 1996.

SCHUSTER, Federico. Social protest in contemporary Argentina: Is there anything new? Universidad de Buenos Aires, Copia fotostática, 1998.

SCRIBANO, Adrián. (s/f.) Los otros, nosotros, y ellos: hacia una caracterización de las practicas políticas en contextos de exclusión. Copia fotostática.

SCRIBANO, Adrián. Argentina cortada: cortes de ruta 'y visibilidad, el contexto del ajuste. En: López Maya, M. (Ed.) Protesta popular en America Latina en los años del neoliberalismo. Venezuela, en prensa, 1998.

PIÑEIRO, Diego. Formas de resistencia de la agricultura familiar. Montevideo: CIESU, 1985.

PIÑEIRO, Diego. Cambios y permanencias en el agro uruguayo. En: GIARRACCA, N. y CLOQUELL, S. (Comp.). Agriculturas del Mercosur: el papel de los actores sociales. Buenos Aires: Ed. La Colmena, 1998.

PIÑEIRO, Diego. Las organizaciones de trabajadores y empresarios y los vaivenes del Mercosur. Ponencia presentada al IX Congreso Brasileño de Sociología, UFRGS, Porto Alegre, 1999.

TARROW, Sidney. El poder en movimiento. Los movimientos sociales, la acción colectiva y la política. Buenos Aires: Alianza Universidad, 1997.

TOURAINE, Alain. La parole et le sang. Paris: Odile Jacob, 1988. 
Sociologias, Porto Alegre, ano 4, no 8, jul/dez 2002, p. 246-274

\section{Resumen}

Cuando el mundo agrario paracía haber entrado en la etapa agroindustrial, con aplicación de altas tecnologías e inexorables desplazamientos poblacionales, la cuestión de la tierra y del acceso a ella o la lucha por conservarla, se convierten en la América Latina atravesada por las políticas neoliberales, en problemas de primer orden. El trabajo trata de mostrar que esta nueva centralidad de las luchas por la tierra es una situación de fines de siglo XX y comienzos del XXI y amerita conceptualizaciones de estos nuevos tiempos. Para tal objetivo revisa los enfoques de mitad del siglo XX y presenta las nuevas conceptualizaciones postestructuralistas.

Pero las nuevas conceptualizaciones, no clasistas, pueden dar lugar a considerar que toda lucha agraria es una lucha por una sociedad más justa e igualitaria. El trabajo toma, justamente, acciones de agricultores de Uruguay y Argentina, donde los reclamos son de tipo corporativos y no pueden asemejarse a las luchas de los sectores subalternos por sus derechos perdidos o nunca adquiridos. Para el caso argentino se agregan los nuevos movimientos de campesinos, chacareras endeudadas, etc. que en los noventa preanunciaron las grandes rebeliones de fines de 2001. Fue la "nueva protesta agraria".

Palabras-claves: movimientos sociales, acciones colectivas, acciones corporativas, nuevas y viejas protestas agrarias, Conosur. 